\title{
Effects of solar radiation on barnacle settlement, early post-settlement mortality and community development in the intertidal zone
}

\author{
Louis A. Gosselin ${ }^{1,2, *}$, Lisa A. Jones ${ }^{1,3}$ \\ ${ }^{1}$ Department of Biological Sciences, Thompson Rivers University, 900 McGill Road, Kamloops, British Columbia V2C 5N3, \\ Canada \\ ${ }^{2}$ Department of Biology, University of Victoria, Victoria, British Columbia V8W 3N5, Canada \\ ${ }^{3}$ Present address: Department of Biology, Redpath Museum, McGill University, 859 Sherbrooke St. West, Montreal, \\ Quebec H3A 2K6, Canada
}

\begin{abstract}
We examined the role of solar radiation, and particularly the role of ultraviolet radiation (UVR), in regulating small-scale settlement patterns and early post-settlement mortality in the barnacle Balanus glandula, as well as community development of sessile organisms colonizing the upper mid-intertidal zone. Settlement of B. glandula cyprids was similar in treatments with and without UVR, suggesting that UVR does not directly influence site selection by cyprids. Once attached, mortality during the 1 to $2 \mathrm{~d}$ period from attachment to metamorphosis ranged from 60 to $100 \%$, and half of the settlers that did metamorphose died during the following $5 \mathrm{~d}$. Mortality during the period from attachment to metamorphosis was significantly lower in locations protected from UVR than in locations exposed to the full spectrum of solar radiation, but only by ca. $10 \%$. Furthermore, UVR exposure had no detectable effect on the mortality rate of metamorphosed early juveniles. Ambient UVR levels also appear to have had little effect on the colonization of mid-intertidal habitats by sessile organisms: our study locations were colonized by 2 sessile invertebrate species and 2 algal species over a period of 2.5 mo in mid-summer, and densities of these species were similar in treatments with and without UVR. Nevertheless, solar radiation dose explained 43 to $65 \%$ of the variation in mortality among daily cohorts of B. glandula, and daily cohort mortality was often $100 \%$ during periods with the highest doses. This relationship between solar radiation and survival to metamorphosis was likely due to the effect of solar radiation on desiccation and heat stress. The high sensitivity of early postsettlement mortality rates to solar radiation suggests global climate change may significantly alter patterns of survivorship through this critical stage of life.
\end{abstract}

KEY WORDS: Survivorship · Population regulation · Mortality factors · Cohorts · Recruitment · Ultraviolet radiation $\cdot$ Weather $\cdot$ Desiccation stress

\section{INTRODUCTION}

Anthropogenically induced stressors on coastal marine communities have attracted global concern for their realized and predicted impacts on these ecologically and economically important environments. Research on impacts associated with global climate change and ozone layer depletion in coastal marine systems has been increasing exponentially (Harley et al. 2006). For marine intertidal communities, which already exist in physiologically stressful environments (Gosselin \& Chia 1995), global climate change and atmospheric ozone depletion are expected to alter levels of salinity, temperature and desiccation stress, as well as levels of solar ultraviolet radiation (UVR) (Przeslawski et al. 2005). Of particular concern are the impacts of such changes on early life stages of intertidal invertebrates, as these life stages may be more 
vulnerable to physiological extremes than larger juveniles and adults (Gosselin 1997, Przeslawski et al. 2005).

Cohorts of newly settled or newly hatched benthic invertebrates experience high mortality rates that vary over time and space (Gosselin \& Qian 1997) and can have substantial effects on population abundance and distribution (Hunt et al. 2003, Jenkins et al. 2008). However, the identity and relative importance of factors responsible for this mortality remain poorly understood. Solar UVR, which remains elevated due to stratospheric ozone loss and which may also continue to increase with global climate change (Harley et al. 2006, McKenzie et al. 2007), has been proposed as a potentially important cause of mortality for early life stages of some invertebrates (Jokiel 1980, Bingham \& Reitzel 2000). Indeed, a variety of benthic invertebrates, as well as macroalgae, are sensitive to UVR. Documented adverse effects on these organisms include reduced growth rates, developmental defects, inhibition of photosynthesis and death (Jokiel 1980, Bingham \& Reitzel 2000, Chiang et al. 2007, Häder et al. 2007, Zacher et al. 2007, Nahon et al. 2009). Marine organisms can achieve some degree of resistance by producing structures or substances that absorb UVR, such as a shell, cuticle, pigmentation or mycosporinelike amino acids, or through mechanisms that repair damaged nucleic acids (Mitchell \& Karentz 1993, Adams \& Shick 2001, Häder et al. 2007, Obermüller et al. 2007). During early life stages, however, these protective structures are not yet fully developed, and their cells, all of which are close to the body surface, are still rapidly dividing and thus potentially very sensitive to mutagenic agents. It is therefore during these early life stages that marine invertebrates are likely to be most vulnerable to UVR (Jokiel 1980, Bingham \& Reitzel 2000).

Marine organisms that experience the greatest exposure to UVR are those living at or close to the water-atmosphere interface. In temperate coastal regions, 90 to $99 \%$ of incident UVR is absorbed in the top $2 \mathrm{~m}$ of the water column (Kuhn \& Browman 1999, Chiang et al. 2007, authors' unpubl. data). As a result, temperate marine organisms located within $2 \mathrm{~m}$ of the surface during the day, as well as those colonizing intertidal and shallow subtidal habitats, will be exposed to high levels of UVR. Of all marine habitats, the highest levels of UVR occur in intertidal habitats that experience daytime low tides during the summer. Yet the effects of UVR on newly settled or newly hatched invertebrates in the intertidal zone have received little attention and, therefore, remain speculative. This may be due in part to the confounding effects of desiccation stress and temperature, both of which can cause mortality in new settlers (Gosselin \& Qian 1997) and co- vary with UVR intensity in the intertidal zone. Currently available and relatively inexpensive light filters (e.g. acrylic, Mylar®) that selectively filter out UVR provide a means to experimentally distinguish the effects of UVR from those of desiccation and heat stress.

Exposure to UVR in the intertidal zone varies with intertidal height (duration of full UVR exposure increases with intertidal height), season (UVR intensity is highest in the summer), time of day (UVR intensity is highest at solar noon), weather (UVR intensity increases with decreasing atmospheric moisture and cloud cover) and amount of shading (UVR intensity is lower under rocks and algae than on exposed surfaces). Thus, to minimize the harmful effects of UVR exposure during the early post-settlement period, sessile invertebrates could reproduce at a time of year such that settlement to intertidal habitats would occur when UVR intensities are lowest (e.g. in winter). Many species, however, reproduce in the spring or summer when primary production is high; this leads to offspring being produced when food availability is highest, but also when UVR intensity is highest. These species may nevertheless reduce their exposure to UVR during the early post-settlement period by settling on days when UVR intensity is low or by selecting microhabitats protected from UVR when settling. The present study focuses on the latter 2 mechanisms among upper mid-intertidal species recruiting in the spring and summer when UVR levels are high.

Larvae of benthic invertebrates actively select settlement sites, and the surface biofilm plays a prominent role in the site selection process. The composition of the bacterial community in the biofilm, and possibly the diatom community, are often key determinants of where invertebrate larvae (Huang \& Hadfield 2003, Qian et al. 2003, Bao et al. 2007), as well as macroalgal spores (Patel et al. 2003), attach and begin benthic life. The composition of bacteria and diatom communities is, in turn, influenced by environmental factors, including UVR. Marine bacteria differ substantially in their responses to UVR (Joux et al. 1999), and UVR alters the development and species composition of biofilm communities (Santas et al. 1997, 1998, Dobretsov et al. 2005, 2010). Competent larvae might therefore be able to distinguish biofilms that have developed under low UVR conditions from those exposed to high levels of UVR, and thus selectively attach in microhabitats that are protected from UVR (Kuffner 2001).

The purpose of the present study was to distinguish the role of UVR from that of desiccation and heat stress in regulating small-scale settlement patterns, early postsettlement mortality and community development of upper mid-intertidal sessile organisms. To achieve this, we focused our study on the barnacle Balanus glandula, a 
species that experiences early post-settlement mortality rates that are high and variable from day to day (Gosselin \& Qian 1996), and on the community of sessile organisms that colonize the upper mid-intertidal zone. We specifically examined (1) if $B$. glandula cyprids select settlement sites based on whether the surface is regularly exposed to UVR; (2) whether day-to-day variation in $B$. glandula settlement rate is related to the corresponding daily ambient levels of UVR; (3) the proportion of early post-settlement mortality in $B$. glandula that is attributable to UVR; and (4) the effect of UVR on the colonization of the upper mid-intertidal zone by sessile organisms over a period of $2.5 \mathrm{mo}$.

\section{MATERIALS AND METHODS}

Study sites and organisms. The present study was carried out from 6 June to 26 August 2001 on Wizard Islet in Barkley Sound on the west coast of Vancouver Island, British Columbia, Canada. Two study sites, located $50 \mathrm{~m}$ apart, were established on the islet: Site A, at the southwestern end of the islet $\left(48^{\circ} 51^{\prime} 27.13^{\prime \prime} \mathrm{N}\right.$, $125^{\circ} 09^{\prime} 38.30^{\prime \prime} \mathrm{W}$, orientation: $160^{\circ} \mathrm{W}$ ), and Site $\mathrm{B}$, on the southeastern side of the islet $\left(48^{\circ} 51^{\prime} 27.62^{\prime \prime} \mathrm{N}\right.$, $125^{\circ} 09^{\prime} 35.87^{\prime \prime} \mathrm{W}$, orientation: $\left.110^{\circ} \mathrm{E}\right)$. The effect of UVR on daily settlement and survival was examined at Site A. Community development over the summer was examined at Sites A and B.

The mid and upper sections of the intertidal zone at both sites consist of bedrock that forms a gently sloping bench. The upper mid-intertidal zone around the perimeter of the islet is densely colonized by Balanus glandula. Juvenile and adult $B$. glandula are found within a vertical band at tidal heights ranging from $\sim 1.6$ to $3.4 \mathrm{~m}$ above mean lower low water, with the highest densities occurring within the 2.4 to $3.0 \mathrm{~m}$ range. This range of tidal heights is emersed for 8 to $9 \mathrm{~h}$ per tide cycle, and at high tide is never more than $1 \mathrm{~m}$ below the surface; it is therefore highly exposed to ambient solar radiation. At both study sites, the community within that range of intertidal heights also included the barnacle Chthamalus dalli, the brown alga Fucus sp., the snails Littorina spp. and Nucella ostrina, the limpet Collisella digitalis and the mussel Mytilus trossulus. An important consideration in selecting Wizard Islet for this study is that the terrestrial part of the islet rises to an elevation of no more than $3 \mathrm{~m}$ above the high tide line and has no trees, such that neither of the 2 experimental sites is shaded from ambient solar radiation by land structures at any time of the day.

Study locations and experimental treatments. At each of the 2 study sites, we selected up to 30 locations within a $15 \mathrm{~m}$ horizontal section of shoreline. These study locations were selected based on the following characteristics: (1) being within the Balanus glandula zone; (2) having at least a $12 \mathrm{~cm}$ diameter circular area of flat rock surface; (3) the rock surface being horizontal or on a very modest slope; (4) not being located in a tidepool; and (5) being already colonized by several juvenile or adult B. glandula. The intertidal heights of all locations were within a relatively narrow 2.5 to $3.0 \mathrm{~m}$ range. On 5 June 2001, all 26 locations at Site A and 30 locations at Site B were scraped to remove all macroscopic organisms, and a hole was drilled in the centre of each location to insert a plastic plug and fasten a stainless steel screw. To remove the biofilm as well as remains of animals and macroalgae, the rock surface within $10 \mathrm{~cm}$ of the hole was scrubbed with a metal-wire brush, rinsed with freshwater and sterilized by burning using a propane torch.

After sterilizing the surfaces, the locations at each site were sequentially numbered and then randomly assigned to one of 3 experimental treatments: full spectrum (Site $A, n=8$; Site $B, n=10$ ), visible only (Site $A$, $\mathrm{n}=9$; Site $\mathrm{B}, \mathrm{n}=10$ ) and control (Site A, $\mathrm{n}=9$; Site $\mathrm{B}$, $\mathrm{n}=10$ ). The full spectrum treatment involved mounting a $12 \mathrm{~cm}$ diameter acrylic disk $1 \mathrm{~cm}$ above the rock surface (Fig. 1). The disks used for this treatment were

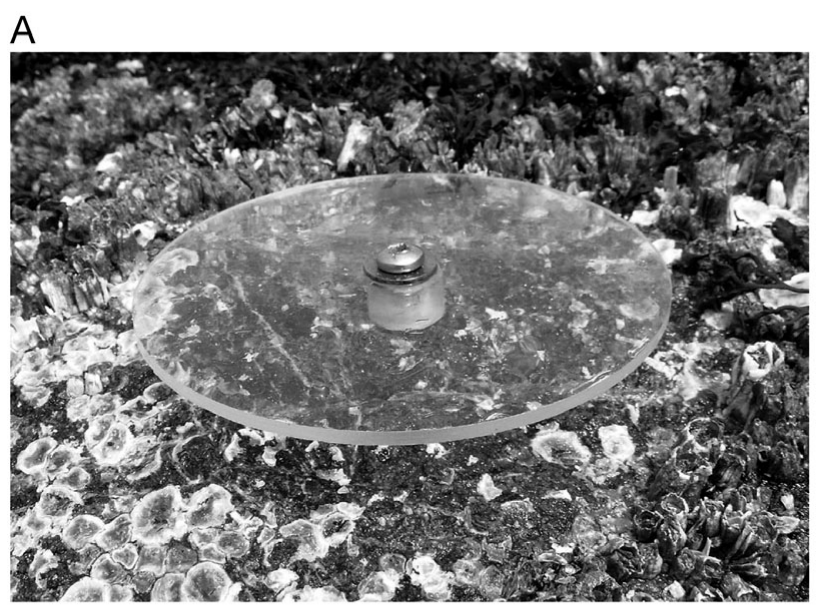

B

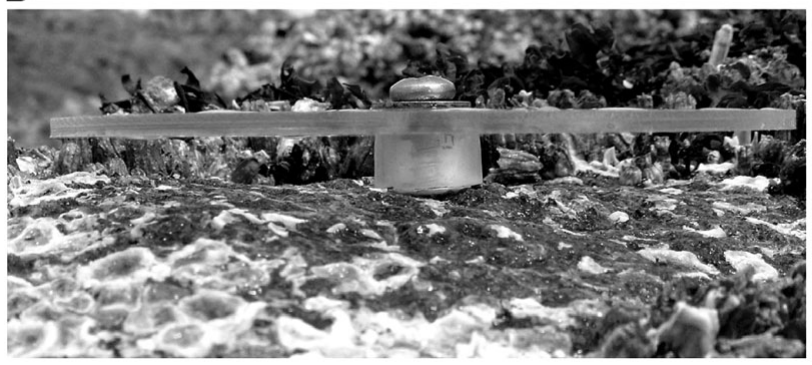

Fig. 1. A study location on Wizard Islet, Vancouver Island, at the start of the experiment. (A) top and (B) side views of the cleared rock surface and the attached acrylic filter disk, as used in the full spectrum and the visible only treatments 
cut from sheets of Acrylite ${ }^{\circledR}$ OP4 acrylic, which is 85 to $92 \%$ transparent to UVR and visible wavelengths (300 to $700 \mathrm{~nm}$ ) (Fig. 2). For the visible only treatment, we attached a $12 \mathrm{~cm}$ diameter Acrylite ${ }^{\circledR}$ OP3 acrylic disk above each surface; OP3 is $92 \%$ transparent to most visible wavelengths but blocks all UVA and UVB (Fig. 2). Finally, no disks were installed at the locations assigned to the control treatment, leaving those rock surfaces fully exposed; this treatment served as a control for any effects the acrylic filter disks might have other than light transmission. The locations used in the control treatment were otherwise prepared in the same way as the 2 other treatments, including a screw fastened in the central hole. All disks in the full spectrum and visible only treatments were replaced with a clean disk once every 2 wk throughout the study period; no traces of fouling or sedimentation were apparent on the disks after each of these intervals, and none of the disks were damaged or dislodged during the study.

Settlement rate and post-settlement mortality. To quantify settlement rate and post-settlement mortality in each treatment, we recorded all new settlers and their subsequent fate within a $6 \mathrm{~cm}$ diameter area of rock surface centred on the hole at each location. The surveyed area at each location, excluding the central hole, was $27.5 \mathrm{~cm}^{2}$. Acrylic filter disks (12 cm diameter) were intentionally much larger than the surveyed area (6 $\mathrm{cm}$ diameter) to avoid surveying rock surfaces that were close to the edge of the disks and thus potentially exposed to oblique light passing under the disk's edge. The disks were installed on 6 June, and the rock surface at each location was then surveyed daily from 7 to 20 June. Surveys involved careful inspection of the

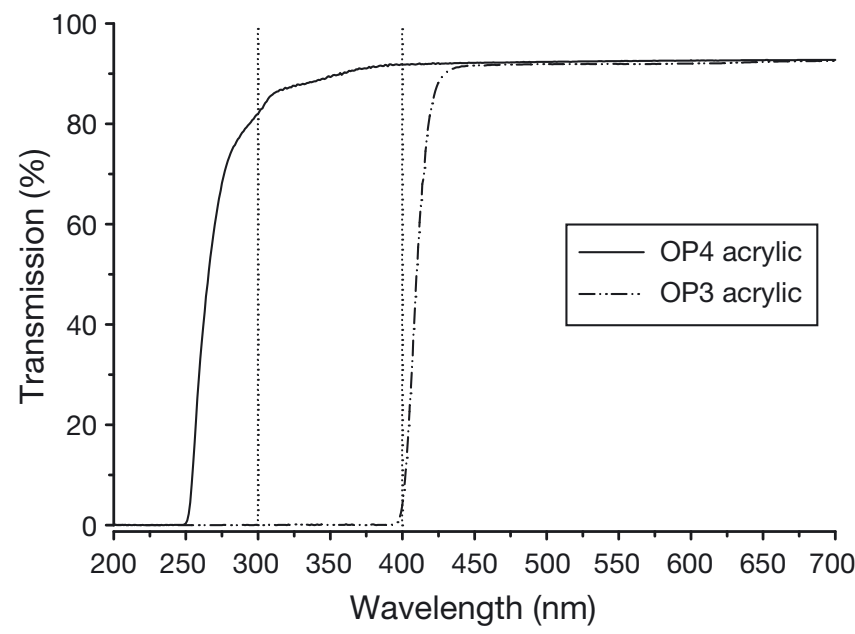

Fig. 2. Light transmission of the Acrylite ${ }^{\circledR}$ OP3 and OP4 acrylic disks used in the present study, as measured with a scanning spectrophotometer. The 2 vertical dotted lines indicate the range of ultraviolet wavelengths $(300-400 \mathrm{~nm})$ that reach the surface of the earth rock surface within the $6 \mathrm{~cm}$ diameter area at each location using a $20 \times$ magnifying lens, and mapping all new and previous settlers on acetate transparency sheets. Only settlers appearing on and after 8 June were included in data analyses, thus allowing $2 \mathrm{~d}$ for the biofilms in each treatment to develop before beginning to assess settlement patterns. This daily mapping also allowed us to monitor the fate of all individuals that settled during the study period as either (1) attached cyprid, (2) dislodged (missing), (3) metamorphosed live early juvenile, or (4) metamorphosed dead early juvenile. Dead individuals were carefully removed using a needle probe. While new settlers were recorded up to 17 June, daily monitoring continued until 20 June, but only to determine the fate of individuals that had already settled. This enabled us to document the proportion of attached cyprids that completed metamorphosis as well as the early juvenile survivorship of all individuals that had metamorphosed during the 8 to 15 June period for the first $5 \mathrm{~d}$ following metamorphosis.

We did not quantify larval abundance in the water column. However, all study locations at each site were within a $15 \mathrm{~m}$ length of shoreline, and replicate locations of each treatment were randomly distributed along the full length of each study area. Furthermore, replicates of a given treatment were only 20 to $40 \mathrm{~cm}$ away from replicates of other treatments. This experimental design was used to ensure exposure to the same range of cyprid densities across all 3 treatments. Finally, during the period of 6 to 20 June, ambient UVR levels were monitored at $4 \mathrm{~min}$ intervals, $24 \mathrm{~h}$ a day, using a Solar Light photometer model PMA 2100 with a UV detector model PMA 2102 - a broadband detector that is most sensitive to UVB. The UV detector was set up $4 \mathrm{~m}$ above the ocean surface, at the nearby Bamfield Marine Sciences Centre, $3 \mathrm{~km}$ from Wizard Islet.

Colonization by sessile species. To determine the influence of UVR on the colonization of upper midintertidal rock surfaces by sessile organisms throughout the summer, all acrylic filter disks were left in place until 25 August $2001-2.5$ mo after initiating the experiment. All sessile species that had colonized the rock surfaces at each location during that period were identified and counted. We anticipated that densities of sessile species in late August might be low, and thus decided to increase sampling effort by adding more locations for each treatment; however, since there were no more suitable locations at Site A, sampling effort was increased by adding 30 locations (10 per treatment) at nearby Site B.

Parameters quantified. The parameters recorded in this experiment were: ambient UVR intensity at $4 \mathrm{~min}$ intervals; intertidal height of each replicate location; daily number of attached cyprids in each location; pro- 
portion of attached cyprids that survived to complete metamorphosis; time taken by newly attached cyprids to complete metamorphosis; survivorship of newly metamorphosed early juveniles during the first $5 \mathrm{~d}$ post-metamorphosis; and abundance of all sessile species present at each location 2.5 mo post-disturbance.

\section{RESULTS}

\section{Effects of UVR on cyprid settlement patterns}

We examined whether settlement was influenced by the light treatment by comparing the total number of cyprids settling at each location over the settlement monitoring period (8 to 17 June) among the 3 treatments at Site A. There was no significant difference among treatments in the average number of attached cyprids per location (ANOVA: $F=0.617$, $\mathrm{df}=2, \mathrm{n}=26$, $\mathrm{p}=0.548$ ), suggesting that the exposure of intertidal rock surfaces to UVR had no effect on the distribution of Balanus glandula settlers. The overall average $( \pm \mathrm{SE})$ for all locations was $1.9 \pm 0.4$ settlers per location per day. In addition, the lack of any significant difference between the control treatment and the 2 other treatments indicates that the presence of an acrylic disk did not influence cyprid settlement to the rock surface underneath.

We also explored whether cyprids preferentially settled on days with low ambient levels of UVR by examining the relationship between the average number of settlers recorded on a given day and the cumulative UVR dose for the previous $24 \mathrm{~h}$ (i.e. the ambient UVR levels just prior to and during settlement). The data set for this analysis therefore consisted of the $24 \mathrm{~h}$ UVR dose $\left(\mathrm{mJ} \mathrm{cm}^{-2}\right)$ and the average number of settlers per location, for each of 9 separate days. For each of the 3 treatments there was no significant relationship between the average number of settlers per location on a given day and the UVR dose for the previous $24 \mathrm{~h}$ period (linear regression: control, $n=9, p=0.798$; full spectrum, $\mathrm{n}=9, \mathrm{p}=0.882$; visible only, $\mathrm{n}=9$, $\mathrm{p}=0.252$ ), nor was there a significant relationship when using pooled data from all 3 treatments $(n=27, p=0.606)$.

\section{Effects of UVR on post-settlement mortality}

\section{Proportion of cyprids completing metamorphosis}

We examined the effect of light treatment and $48 \mathrm{~h}$ UVR dose on the fate of daily cohorts of new cyprids appearing in our study locations (i.e. the proportion that completed metamorphosis). The $48 \mathrm{~h}$ UVR dose consisted of the cumulative UVR dose measured over a
$48 \mathrm{~h}$ period centred on the morning when the cyprids were first observed in our study locations (i.e. $24 \mathrm{~h}$ prior to and $24 \mathrm{~h}$ following that morning). This $48 \mathrm{~h}$ time period took into consideration (1) that our surveys took place once a day, and therefore cyprids appearing in our study locations for the first time on a given morning would have attached sometime within the previous $24 \mathrm{~h}$, and (2) that most of the cyprids that completed metamorphosis did so within $24 \mathrm{~h}$ of first being observed in our study locations. The proportion of attached cyprids that completed metamorphosis was then examined using an analysis of covariance (ANCOVA), with light treatment as a factor and $48 \mathrm{~h}$ UVR dose as the covariate (Fig. 3). This analysis led to the following 3 findings.

First, exposure to UVR increased the mortality of attached cyprids by $\sim 10 \%$ relative to that of cyprids shielded from UVR. The slopes of the relationships between the proportion of cyprids completing metamorphosis and the $48 \mathrm{~h}$ UVR dose did not differ among treatments (ANCOVA, arcsine-transformed proportions: $F=0.703, \mathrm{df}=2, \mathrm{n}=27, \mathrm{p}=0.507$ ). However, there was a significant difference among treatments in intercepts (estimated marginal means) $(F=3.910, \mathrm{df}=$ $2, \mathrm{n}=27, \mathrm{p}=0.035)$ : the proportion of attached cyprids that completed metamorphosis in the visible only treatment was higher than in the full spectrum $(\mathrm{p}=0.021)$ and control $(p=0.028)$ treatments by $\sim 10 \%$, but there was no significant difference $(p=0.897)$ between the full spectrum and control treatments, as determined by least significant difference pairwise comparisons among estimated marginal means (Fig. 3).

Second, the proportion of cyprids completing metamorphosis (all treatments and daily cohorts consid-

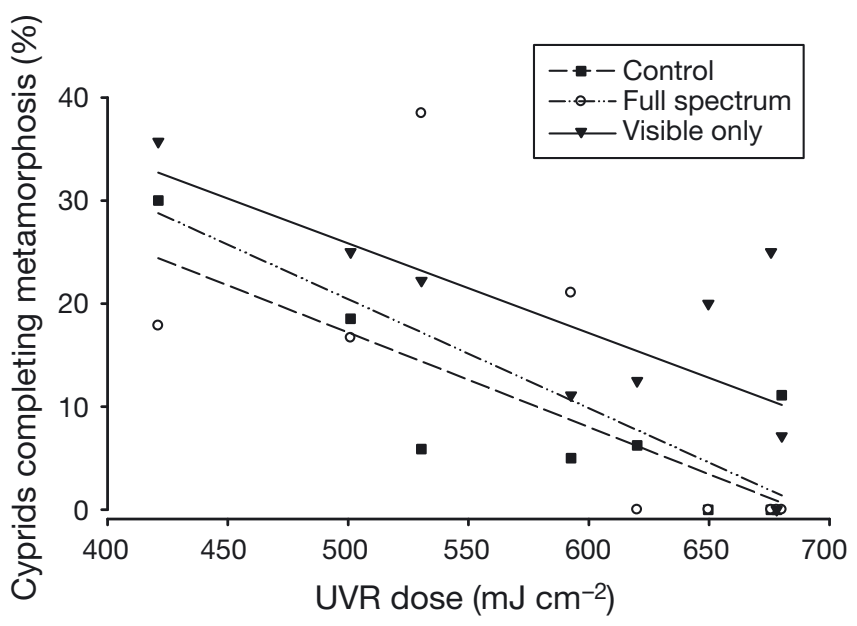

Fig. 3. Relationship between the percentage of cyprids that completed metamorphosis (arcsine-transformed data) and the $48 \mathrm{~h}$ cumulative solar ultraviolet radiation (UVR) dose for each of the 3 light treatments. Regression lines, as determined by ANCOVA, are plotted for each treatment 
ered) ranged from 0 to $38 \%$ (Fig. 3), indicating that (1) survival to metamorphosis was highly variable among daily cohorts, (2) at least $62 \%$ of attached cyprids died before completing metamorphosis even in the absence of UVR, and (3) cohorts of cyprids exposed to ambient light conditions (control and full spectrum treatments) experienced $100 \%$ mortality during periods when the highest UVR doses were recorded (i.e. $\geq 650 \mathrm{~mJ} \mathrm{~cm}^{-2}$ $48 \mathrm{~h}^{-1}$ ).

Finally, there was a significant negative relationship between survivorship from attachment to metamorphosis and the $48 \mathrm{~h}$ UVR dose in each treatment (Fig. 3). Regression analysis revealed that the $48 \mathrm{~h}$ UVR dose explained $43 \%$ (visible only, $\mathrm{n}=9, \mathrm{p}=$ 0.054 ), $62 \%$ (full spectrum, $\mathrm{n}=9, \mathrm{p}=0.011$ ) and $65 \%$ (control, $\mathrm{n}=9, \mathrm{p}=0.009$ ) of the variation in survivorship to metamorphosis among daily cohorts of attached cyprids. It is surprising that this relationship was significant even in the visible only treatment, where settlers were fully shielded from UVR; this suggests that UVR itself was not a direct causal factor in this relationship. Indeed, the occurrence of this relationship in the visible only treatment indicates that much of the variation among daily cohorts in cyprid mortality was due to one or more other factors that covary with UVR dose.

\section{Early juvenile survivorship during the first $5 \mathrm{~d}$} following metamorphosis

Due to the low proportion of attached cyprids that metamorphosed into early juveniles, the number of juveniles in the present study was too low to calculate survivorship separately for each location. We therefore pooled all early juveniles within each treatment to obtain a simple survivorship curve for each treatment. Early juvenile mortality was high, with only half the newly metamorphosed juveniles surviving to Day 5 (Fig. 4). The trends in survivorship, however, were similar among the 3 treatments and the proportions surviving to an age of $5 \mathrm{~d}$ were not significantly different among treatments (multiple comparisons test for proportions, Zar 1984: $\chi^{2}=0.0384, \mathrm{df}=2, \mathrm{n}=49, \mathrm{p}>$ 0.97). Early juveniles in the visible only treatment did not have higher survivorship than in the 2 other treatments.

\section{Effect of UVR on colonization by sessile species during the summer}

A total of 4 species colonized the study locations at Sites A and B by 25 August, 2.5 mo after clearing the rock surfaces: the barnacles Balanus glandula and

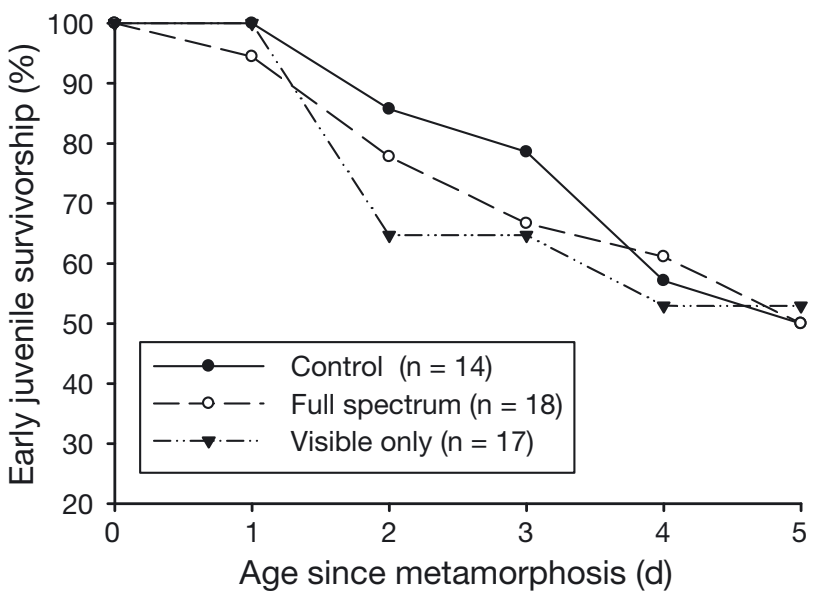

Fig. 4. Balanus glandula. Survivorship of early juvenile $B$. glandula over the first $5 \mathrm{~d}$ after metamorphosis in each of the 3 light treatments. Each survivorship value is calculated from all settlers (pooled from all replicate locations) that completed metamorphosis in the given treatment early enough in the study to monitor their fate for at least $5 \mathrm{~d}$ following metamorphosis

Chthamalus dalli, and the algae Fucus sp. and Cladophora columbiana. C. columbiana was only found at 5 of the 56 locations, whereas B. glandula, $C$. dalli and Fucus sp. were found in 20,33 and 16 of the study locations, respectively. For each of the latter 3 species, the densities in the study locations on 25 August were separately examined using 2-way ANOVAs, with light treatment and site as fixed factors (Fig. 5). The analyses for each of the 3 species revealed no significant interactions between factors (ANOVA: B. glandula, $F=0.318, \mathrm{df}=2, \mathrm{n}=56, \mathrm{p}=0.719$; C. dalli, $F=0.372, \mathrm{df}=2, \mathrm{n}=56, \mathrm{p}=0.691 ;$ Fucus sp. $F=0.089$, $\mathrm{df}=2, \mathrm{n}=56, \mathrm{p}=0.915$ ) and no significant differences in densities among light treatments $(B$. glandula, $F=$ 1.201, df $=2, \mathrm{n}=56, \mathrm{p}=0.31 ; C$. dalli, $F=0.068, \mathrm{df}=2$, $\mathrm{n}=56, \mathrm{p}=0.935$; Fucus $\mathrm{sp} ., F=0.321, \mathrm{df}=2, \mathrm{n}=56, \mathrm{p}=$ 0.727 ), indicating that neither UVR nor the disks themselves affected the colonization process by these species. Site differences were observed in $C$. dalli $(F=$ 5.963, df =1, $\mathrm{n}=56, \mathrm{p}=0.018$ ), with higher densities at Site $B$, but not in B. glandula $(F=1.757$, df $=1, \mathrm{n}=56$, $\mathrm{p}=0.191)$ or in Fucus sp. $(F=2.464, \mathrm{df}=1, \mathrm{n}=56, \mathrm{p}=$ $0.123)$.

\section{Time to complete metamorphosis}

By monitoring the settlement of new individuals and the fate of each settler once a day, we were able to determine the time required for a cyprid to complete metamorphosis once it had attached, with an accuracy of $\pm 24 \mathrm{~h}$. Of the 555 cyprids that settled in our study 


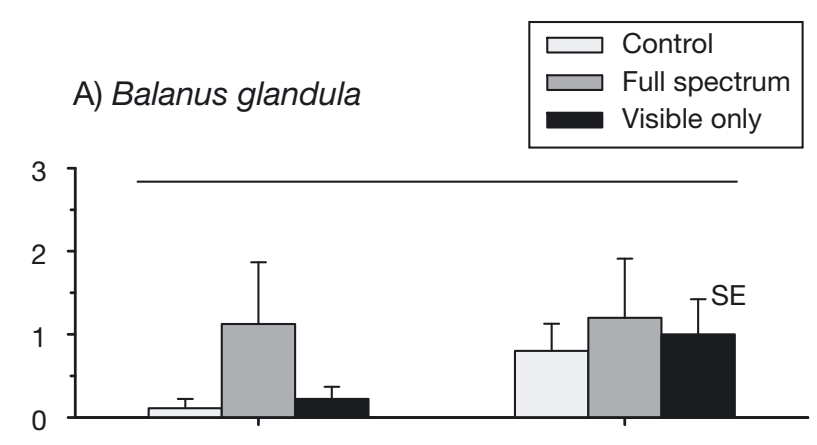

B) Chthamalus dalli

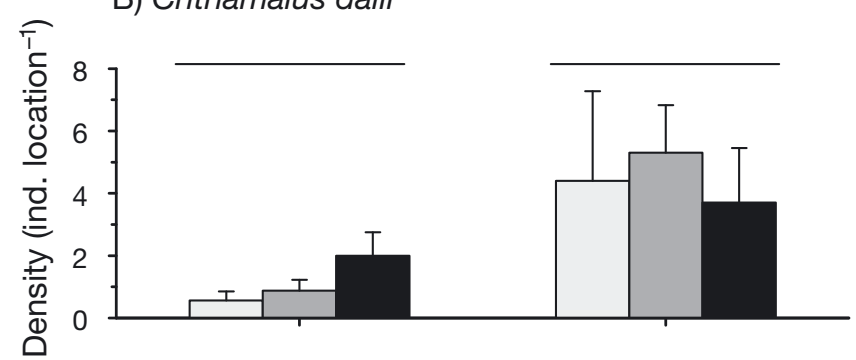

C) Fucus sp.

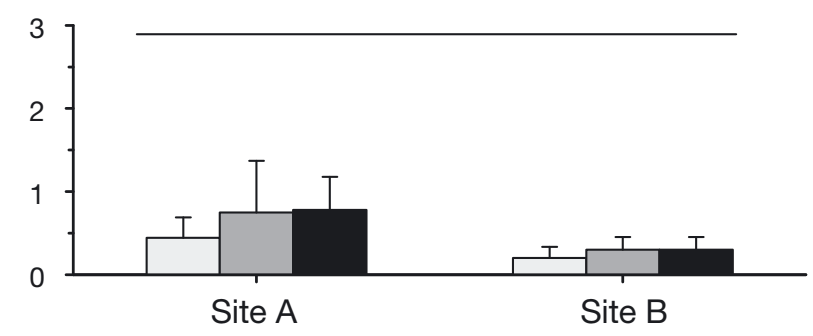

Fig. 5. Average densities of the 3 most commonly found species in the study locations on 25 August 2001, i.e. 2.5 mo after the rock surfaces had been cleared and sterilized, and the light treatments begun. The surface area of each replicate location was $27.5 \mathrm{~cm}^{2}$. Horizontal lines above a graph link values that are not significantly different based on 2-way ANOVAs. Error bars are + SE

locations during the 8 to 17 June period, 108 (19.5\%) metamorphosed into early juveniles. Of these 108 settlers, $84.2 \%$ metamorphosed within the first day after settlement, and $13.9 \%$ metamorphosed 1 to $2 \mathrm{~d}$ postsettlement. Only 2 cyprids $(1.9 \%)$ were found to have metamorphosed 2 to $4 \mathrm{~d}$ after settlement. In these 2 cases, it is possible that the original cyprid became dislodged at some point and was replaced by a new cyprid that attached in the exact same location within the $1 \mathrm{~d}$ interval between our inspections, in which case metamorphosis would have occurred within the first $2 \mathrm{~d}$ even in these 2 cases. Therefore, most, if not all, individuals that successfully metamorphosed did so within $2 \mathrm{~d}$ of settlement.

\section{DISCUSSION}

\section{Effects of UVR on cyprid settlement patterns}

Balanus glandula cyprids settled equally in all treatments in the present study, indicating that their settlement behaviour does not include the avoidance of UVR-exposed surfaces. The number of cyprids settling in our study locations on a given day was also unrelated to the UVR dose during the $24 \mathrm{~h}$ period when selection of attachment location and attachment to the rock surface would occur. We did not monitor larval abundances in the water column, and so our results provide an indirect assessment of settlement intensity as a function of daily levels of UVR. Nevertheless, our findings suggest $B$. glandula cyprids do not preferentially settle on days with low UVR. We conclude that UVR does not directly influence site selection by $B$. glandula cyprids settling in the intertidal zone, nor does it appear to play a role in determining day-to-day variation in settlement intensity.

\section{Effects of UVR on post-settlement mortality}

Most settlers that metamorphosed did so within $1 \mathrm{~d}$ after settlement, and those that were not able to metamorphose within the first $2 \mathrm{~d}$ died before completing metamorphosis. The time window for completing metamorphosis is therefore quite narrow in Balanus glandula. Average survivorship during this brief period from attachment to metamorphosis in the control treatment (which most closely emulated natural conditions) was $13.6 \%$, and only half of the settlers that metamorphosed survived to become $5 \mathrm{~d}$ old early juveniles. These low survivorship values are consistent with previous reports of high early post-settlement mortality in barnacles (Minchinton \& Scheibling 1993, Gosselin \& Qian 1996, Jarrett 2000). The densities of live $B$. glandula that were present in our study locations on 25 August, 2.5 mo post-disturbance, represent only $2.4 \%$ of the number of cyprids that settled in these same locations over the $10 \mathrm{~d}$ period during which we monitored settlement (8 to 17 June). Given that settlement was still occurring when we last surveyed new settlers on 17 June, the densities observed on 25 August therefore represent less than $2.4 \%$ of all the settlers that attached to those rock surfaces throughout the entire 8 June to 25 August period. This suggests that $>90 \%$ of the mortality occurring over the interval from attachment to maturity would occur during the first 6 to $7 \mathrm{~d}$ after attachment. This is evidence that the early post-settlement period constitutes a bottleneck period for recruitment (Gosselin \& Qian 1997) which can potentially have a sub- 
stantial effect on population abundance and dynamics (Jenkins et al. 2008).

UVR exposure caused increased mortality levels during the brief period from attachment to metamorphosis: survivorship in UVR protected locations was $\sim 10 \%$ higher than in the 2 treatments in which settlers were exposed to UVR. This sensitivity of barnacle cyprids to UVR is consistent with reports of UVR damaging tissues in barnacle nauplii and cyprids (Chiang et al. 2007). However, the relatively low proportion of settlers dying from UVR exposure in the intertidal zone is surprising, given the deleterious effects of UVR on nucleic acids and proteins and the relatively high levels of exposure to UVR in the upper parts of the intertidal zone. Balanus glandula cyprids must therefore possess effective means of resistance, which likely include an exoskeleton that filters out much of the UVR (Sagi et al. 1995, Obermüller et al. 2007), and may also involve UVR absorbing compounds such as mycosporine-like amino acids (Obermüller et al. 2007) and effective DNA repair mechanisms (Mitchell \& Karentz 1993). In contrast, UVR exposure had no detectable effect on the mortality rate of metamorphosed early juveniles. This ontogenetic shift in vulnerability to UVR is likely associated with the addition of a calcareous shell shortly after metamorphosis, effectively shielding the tissues of the young barnacle from UVR.

Although UVR was responsible for some mortality during the attachment to metamorphosis period, mortality during that period was remarkably high, ranging from 60 to $100 \%$, and was also highly variable among daily cohorts, even in the visible only treatment. This indicates that other important mortality factors were involved, and our data provides insight as to the likely identity of these other mortality factors. Much of the mortality occurring during the attachment to metamorphosis period was linked to solar radiation, as revealed by the strong negative relationship in all treatments between survivorship and cumulative UVR dose over the $48 \mathrm{~h}$ period during and after attachment (Fig. 3). The intensity of UVR at the surface of the ocean is highly correlated with the intensity of visible radiation (authors' unpubl. data): days with high levels of UVR also had high levels of visible radiation. Newly attached cyprids may have died as a result of vulnerability to visible wavelengths, as is the case for larvae and juveniles of the ascidian Corella inflata (Bingham \& Reitzel 2000). We propose, however, that the primary mechanism by which solar radiation likely affected early post-settlement mortality was through its influence on desiccation stress, and possibly heat stress, in the intertidal zone. An increase in solar radiation likely leads to an increase in the temperature of intertidal surfaces and in evaporation rate. In addition, high lev- els of solar radiation typically occur on days with clear skies and low relative humidity, further enhancing evaporation rates. Of these 2 factors, desiccation is more likely to be responsible for the high post-settlement mortality of Balanus glandula than heat (Gosselin \& Qian 1997). Early juvenile mortality in the field has been attributed to desiccation stress in barnacles (Denley \& Underwood 1979, Miron et al. 1999), limpets (Wolcott 1973, Branch 1975) and snails (Behrens 1972). Gosselin \& Chia (1995) found newly hatched Nucella ostrina, a mid-intertidal snail that co-occurs with $B$. glandula, to be highly vulnerable to the desiccation conditions, but not to the heat stress conditions, which these animals can experience in Barkley Sound. We are not aware of reports in which intertidal heat stress was specifically found to cause early post-settlement mortality, although it might be lethal to new settlers in warmer tropical and subtropical climates. Further study on the role of desiccation, heat and visible light during the early post-settlement period is needed.

Factors other than solar radiation likely also contributed to early post-settlement mortality, as suggested by the 60 to $65 \%$ mortality experienced on days when solar radiation was at its lowest (i.e. during consistently overcast weather). There was no evidence of predation being responsible for cyprid or early juvenile mortality; the acrylic filter disks would have prevented all but the smallest predators from disturbing the young barnacles, and no difference in mortality was observed between the control and the full spectrum treatments. In addition, no small predators were found under the disks during our surveys, although some, such as small crabs or hermit crabs, might have crawled underneath during the brief periods of immersion at high tide and then left as the tide receded. Other factors potentially responsible for this early mortality include carryover effects from the larval experience (Phillips 2004, Pechenik 2006), particularly those resulting in cyprids lacking sufficient energy reserves at the time of attachment to complete metamorphosis (Jarrett \& Pechenik 1997).

\section{Effects of UVR on recruitment by sessile species}

The colonization of rock surfaces by sessile organisms, including algae, was not affected by UVR over the June to August period, a time of year when solar radiation is at its most intense. By 25 August, 2.5 mo after clearing and sterilizing the rock surfaces, 2 sessile invertebrate species and 2 algal species had colonized the rock surfaces in our study locations; the densities of each of these species were similar in treatments with and without UVR, and the treatment without UVR was not colonized by cryptic or lower intertidal species. This 
finding contrasts our other results showing a significant effect of UVR on Balanus glandula mortality during the attachment to metamorphosis period. In the visible only treatment, release from the relatively modest levels of UVR-induced early post-settlement mortality was likely compensated by either increased mortality to other factors or decreased settlement after 17 June.

\section{CONCLUSIONS}

Newly attached Balanus glandula cyprids are sensitive to ambient levels of UVR in the intertidal zone until they complete metamorphosis, but the relatively modest proportion of early post-settlement mortality attributable to UVR does not appear to influence population density. Similar colonization of each of our light treatments by sessile invertebrate and macroalgal species over a 2.5 mo period in mid-summer suggests ambient UVR levels have little effect on recruitment by sessile organisms inhabiting mid- and upper-intertidal habitats. However, solar radiation dose was a good predictor of mortality during the attachment to metamorphosis period, with daily cohort survivorship often being zero during periods with the highest UVR doses. The relationship between solar radiation and survival to metamorphosis was likely due to the indirect effect of solar radiation conditions on desiccation stress in the intertidal zone. Correspondingly, spatial and temporal variation in early post-settlement survival, and thus in recruitment, may be largely a consequence of variation in factors that control temperature or evaporation rates in the intertidal zone during the settlement period, such as air and intertidal surface temperatures, relative humidity, wind speed and cloud cover. The high sensitivity of early post-settlement mortality rates in $B$. glandula to weather conditions suggests that global climate change may significantly alter patterns of survivorship through this critical stage of life, particularly if the frequency of days with high levels of solar radiation were to change.

Acknowledgements. We thank the director and staff of the Bamfield Marine Sciences Centre for providing facilities, equipment and support during this study. The present study was conducted in compliance with the research ethics requirements of the Animal Care Committee of Thompson Rivers University. This work was supported by the Natural Sciences and Engineering Council (NSERC) and Scholarly Activity Committee grants to L.A.G. and an NSERC Undergraduate Student Research Award to L.A.J.

\section{LITERATURE CITED}

Adams NL, Shick JM (2001) Mycosporine-like amino acids prevent UVB-induced abnormalities during early devel- opment of the green sea urchin Strongylocentrotus droebachiensis. Mar Biol 138:267-280

Bao WY, Satuito CG, Yang JL (2007) Larval settlement and metamorphosis of the mussel Mytilus galloprovincialis in response to biofilms. Mar Biol 150:565-574

Behrens S (1972) The role of wave impact and desiccation on the distribution of Littorina sitkana Philippi, 1845. Veliger 15:129-132

> Bingham BL, Reitzel AM (2000) Solar damage to the solitary ascidian, Corella inflata. J Mar Biol Assoc UK 80:515-521

> Branch GM (1975) Ecology of Patella species from the Cape Peninsula, South Africa. IV. Desiccation. Mar Biol 32: 179-188

> Chiang WL, Wu RSS, Yu PKN, Au DWT (2007) Are barnacle larvae able to escape from the threat of UV? Mar Biol 151: 703-711

> Denley EJ, Underwood AJ (1979) Experiments on factors influencing settlement, survival, and growth of two species of barnacles in New South Wales. J Exp Mar Biol Ecol 36:269-293

> Dobretsov SV, Qian PY, Wahl M (2005) Effect of solar ultraviolet radiation on the formation of shallow, early successional biofouling communities in Hong Kong. Mar Ecol Prog Ser 290:55-65

Dobretsov SV, Gosselin LA, Qian PY (2010) Effects of solar PAR and UV radiation on tropical biofouling communities. Mar Ecol Prog Ser 402:31-43

> Gosselin LA (1997) An ecological transition during juvenile life in a marine snail. Mar Ecol Prog Ser 157:185-194

> Gosselin LA, Chia FS (1995) Characterizing temperate rocky shores from the perspective of an early juvenile snail: the main threats to survival of newly hatched Nucella emarginata. Mar Biol 122:625-635

Gosselin LA, Qian PY (1996) Early post-settlement mortality of an intertidal barnacle: a critical period for survival. Mar Ecol Prog Ser 135:69-75

Gosselin LA, Qian PY (1997) Juvenile mortality in benthic marine invertebrates. Mar Ecol Prog Ser 146:265-282

> Häder DP, Kumar HD, Smith RC, Worrest RC (2007) Effects of solar UV radiation on aquatic ecosystems and interactions with climate change. Photochem Photobiol Sci 6:267-285

> Harley CDG, Hughes AR, Hulgren KM, Miner BG and others (2006) The impacts of climate change in coastal systems. Ecol Lett 9:228-241

Huang S, Hadfield MG (2003) Composition and density of bacterial biofilms determine larval settlement of the polychaete Hydroides elegans. Mar Ecol Prog Ser 260:161-172

> Hunt HL, McLean DA, Mullineaux LS (2003) Post-settlement alteration of spatial patterns of soft shell clam (Mya arenaria) recruits. Estuaries 26:72-81

> Jarrett JN (2000) Temporal variation in early mortality of an intertidal barnacle. Mar Ecol Prog Ser 204:305-308

> Jarrett JN, Pechenik JA (1997) Temporal variation in cyprid quality and juvenile growth capacity for an intertidal barnacle. Ecology 78:1262-1265

> Jenkins SR, Murura J, Burrows MT (2008) Temporal changes in the strength of density-dependent mortality and growth in intertidal barnacles. J Anim Ecol 77:573-584

Jokiel PL (1980) Solar ultraviolet radiation and coral reef epifauna. Science 207:1069-1071

Joux F, Jeffrey WH, Lebaron P, Mitchell DL (1999) Marine bacterial isolates display diverse responses to UV-B radiation. Appl Environ Microbiol 65:3820-3827

$>$ Kuffner IB (2001) Effects of ultraviolet (UV) radiation on larval settlement of the reef coral Pocillopora damicornis. Mar Ecol Prog Ser 217:251-261

Kuhn P, Browman H, McArthur B, St-Pierre JF (1999) Penetration of ultraviolet radiation in the waters of the estu- 
ary and Gulf of St. Lawrence. Limnol Oceanogr 44: $710-716$

McKenzie RL, Aucamp PJ, Bais AF, Björn LO, Ilyas M (2007) Changes in biologically-active ultraviolet radiation reaching the Earth's surface. Photochem Photobiol Sci 6: 218-231

Minchinton TE, Scheibling RE (1993) Variations in sampling procedure and frequency affect estimates of recruitment of barnacles. Mar Ecol Prog Ser 99:83-88

Miron G, Boudreau B, Bourget E (1999) Intertidal barnacle distribution: a case study using multiple working hypotheses. Mar Ecol Prog Ser 189:205-219

Mitchell DL, Karentz D (1993) The induction and repair of DNA photodamage in the environment. In: Young AR (ed) Environmental UV photobiology. Plenum Press, New York, NY, p 345-377

Nahon S, Castro Porras VA, Pruski AM, Charles F (2009) Sensitivity to UV radiation in early life stages of the Mediterranean sea urchin Sphaerechinus granularis (Lamarck). Sci Total Environ 407:1892-1900

- Obermüller B, Puntarulo S, Abele D (2007) UV-tolerance and instantaneous physiological stress responses of two Antarctic amphipod species Gondogeneia antarctica and Djerboa furcipes during exposure to UV radiation. Mar Environ Res 64:267-285

Patel P, Callow ME, Joint I, Callow JA (2003) Specificity in the settlement-modifying response of bacterial biofilms towards zoospores of the marine alga Enteromorpha. Environ Microbiol 5:338-349

Pechenik J (2006) Larval experience and latent effects: metamorphosis is not a new beginning. Integr Comp Biol 46: 323-333

Editorial responsibility: Otto Kinne, Oldendorf/Luhe, Germany
Phillips NE (2004) Variable timing of larval food has consequences for early juvenile performance in a marine mussel. Ecology 85:2341-2346

Przeslawski R, Davis AR, Benkendorff K (2005) Synergistic effects associated with climate change and the development of rocky shore molluscs. Global Change Biol 11: 515-522

Qian PY, Thiyagarajan V, Lau SCK, Cheung SCK (2003) Relationship between bacterial community profile in biofilm and attachment of the acorn barnacle Balanus amphitrite. Aquat Microb Ecol 33:225-237

Sagi A, Rise M, Isam K, Arad S (1995) Carotenoids and their derivatives in organs of the maturing female crayfish Cherax quadricarinatus. Comp Biochem Physiol 112B: 309-313

Santas R, Lianou C, Danielidis D (1997) UVB radiation and depth interaction during the primary succession of marine diatom assemblages of Greece. Limnol Oceanogr 42: 986-991

Santas R, Santas Ph, Lianou Ch, Korda A (1998) Community responses to UV radiation. II. Effects of solar UVB on fieldgrown diatom assemblages of the Caribbean. Mar Biol 131:163-171

Wolcott TG (1973) Physiological ecology and intertidal zonation in limpets (Acmaea): a critical look at 'limiting factors'. Biol Bull 145:389-422

Zacher K, Roleda MY, Hanelt D, Wiencke C (2007) UV effects on photosynthesis and DNA in propagules of three Antarctic seaweeds (Adenocystis utricularis, Monostroma hariotii, and Porphyra endiviifolium). Planta 225: 1505-1516

Zar JH (1984) Biostatistical analysis, 2nd edn. Prentice Hall, Englewood Cliffs, NJ

Submitted: August 17, 2009; Accepted: March 1, 2010

Proofs received from author(s): May 4, 2010 